Supplement of Biogeosciences, 12, 7503-7518, 2015

http://www.biogeosciences.net/12/7503/2015/

doi:10.5194/bg-12-7503-2015-supplement

(C) Author(s) 2015. CC Attribution 3.0 License.

(c) (i)

Supplement of

\title{
Do land surface models need to include differential plant species responses to drought? Examining model predictions across a mesic-xeric gradient in Europe
}

M. G. De Kauwe et al.

Correspondence to: M. G. De Kauwe (mdekauwe@gmail.com)

The copyright of individual parts of the supplement might differ from the CC-BY 3.0 licence. 


\section{Figure S1}
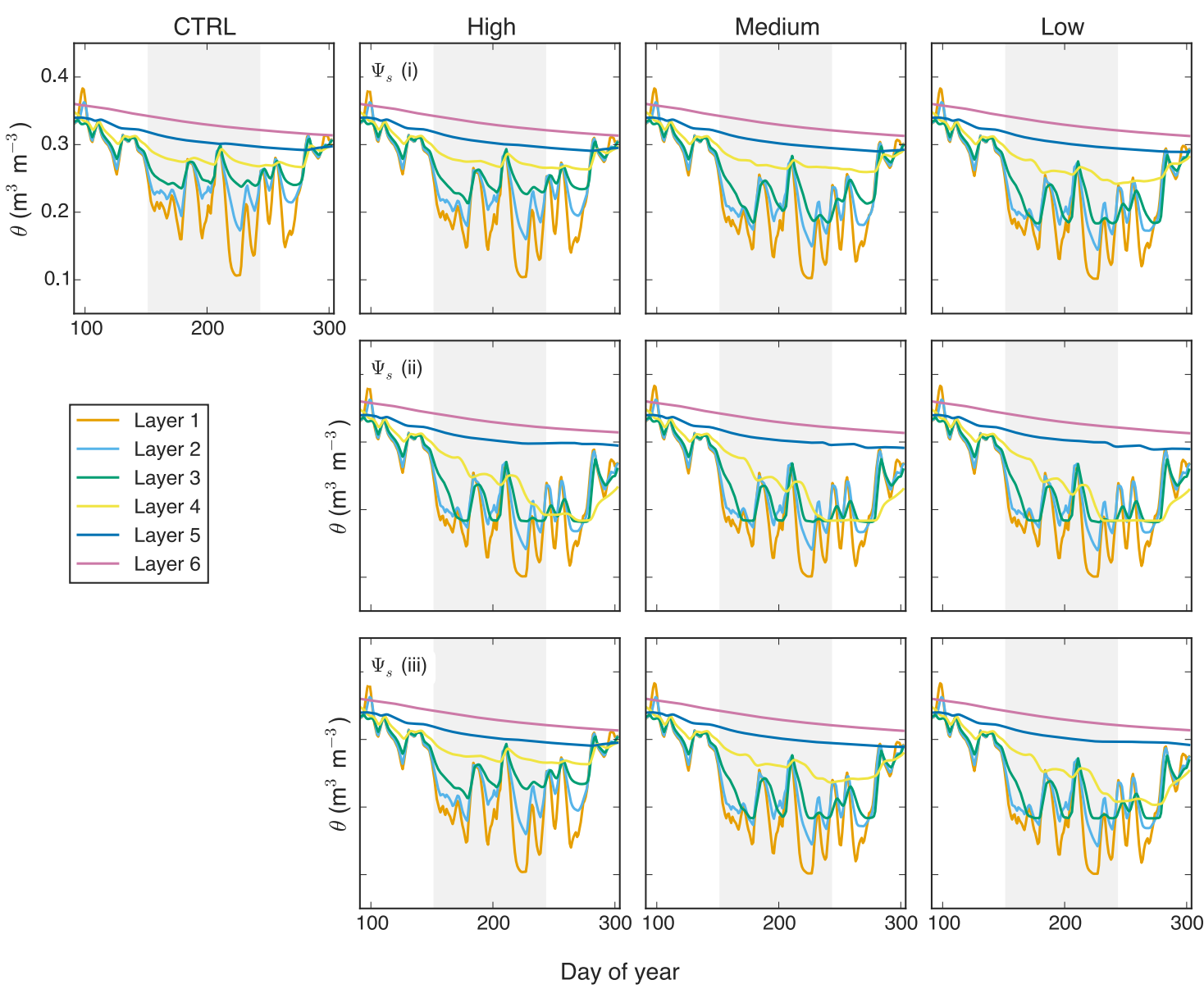


\section{Figure S2}
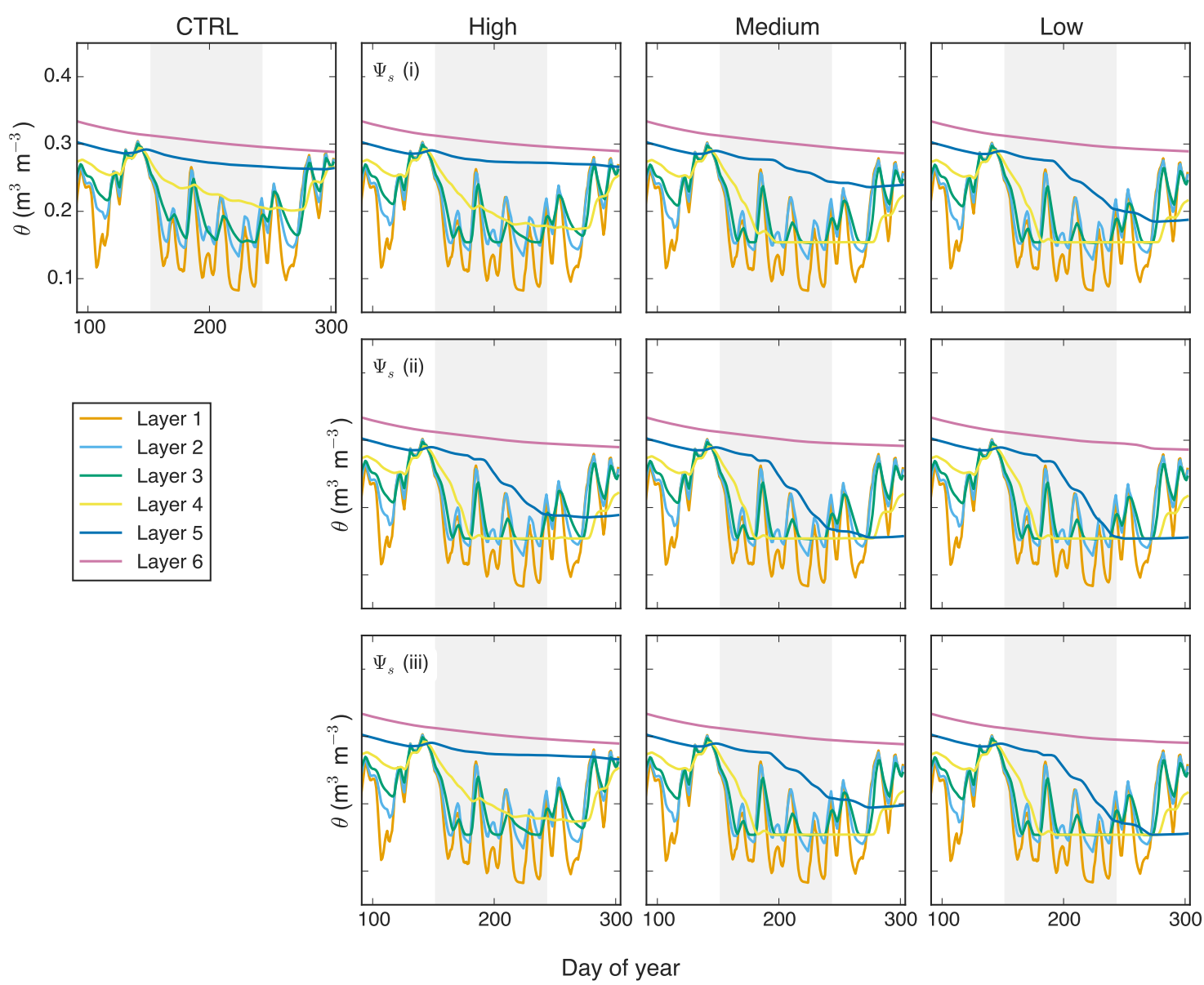


\section{Figure S3}

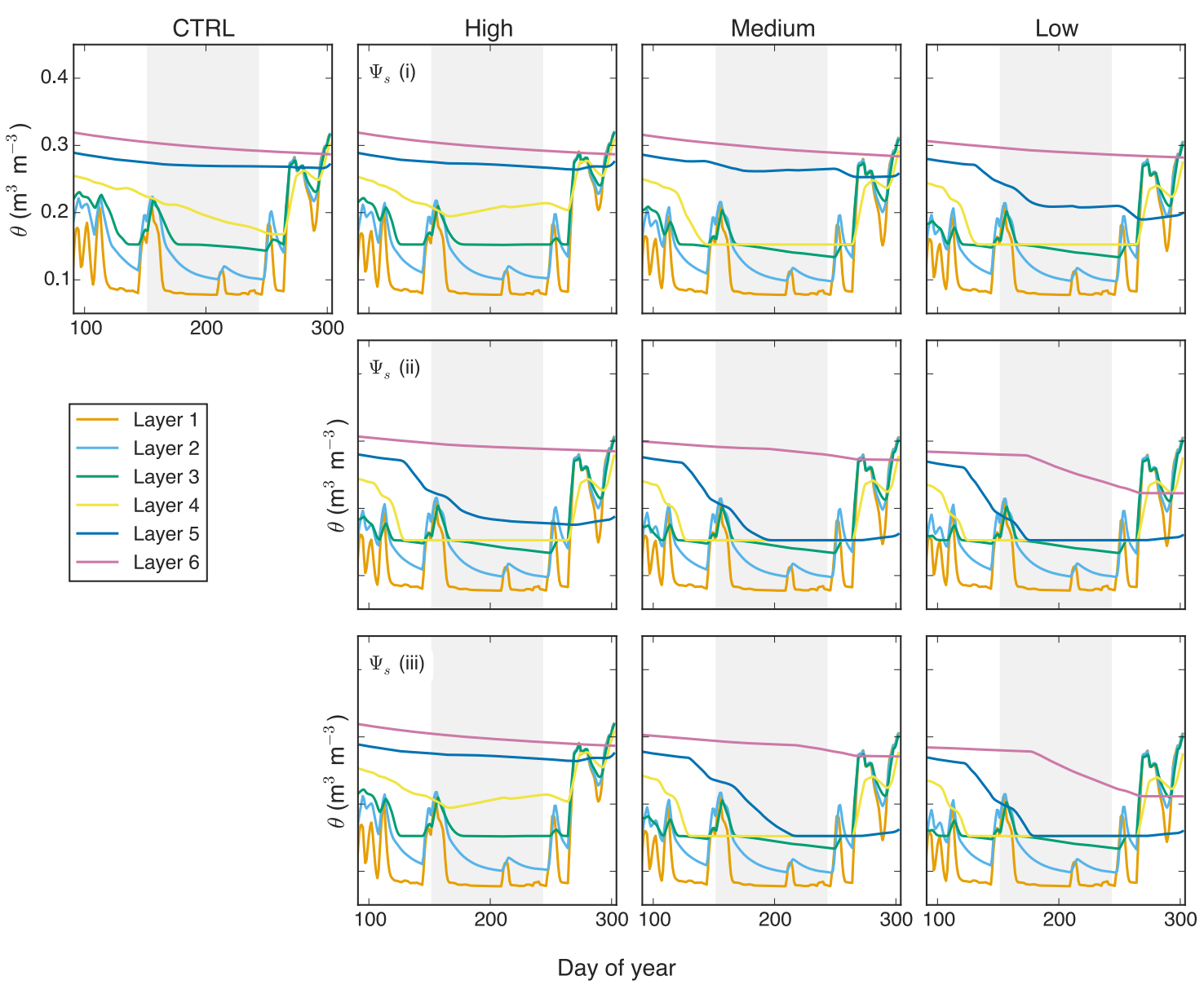




\section{Figure S4}
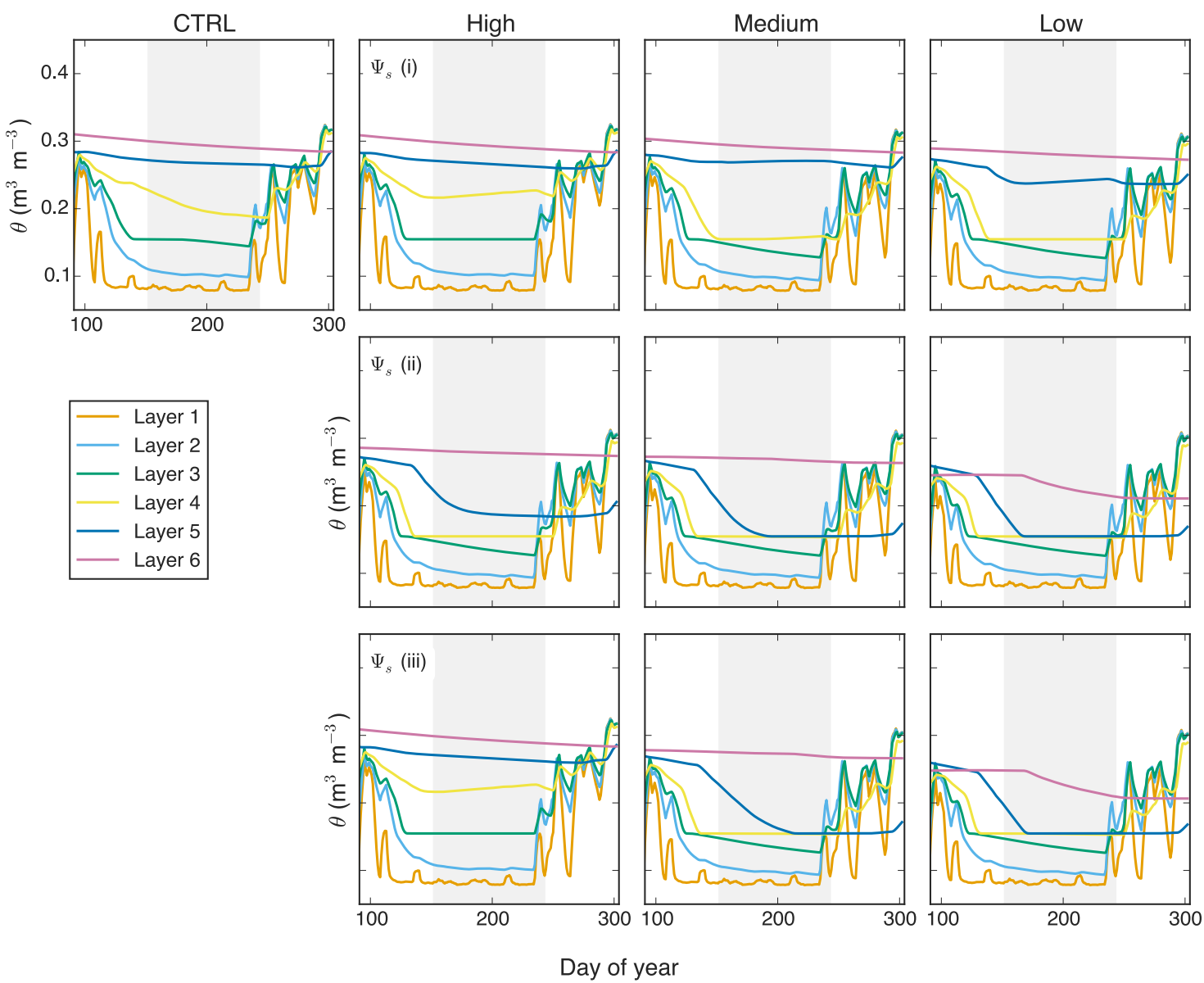


\section{Figure S5}
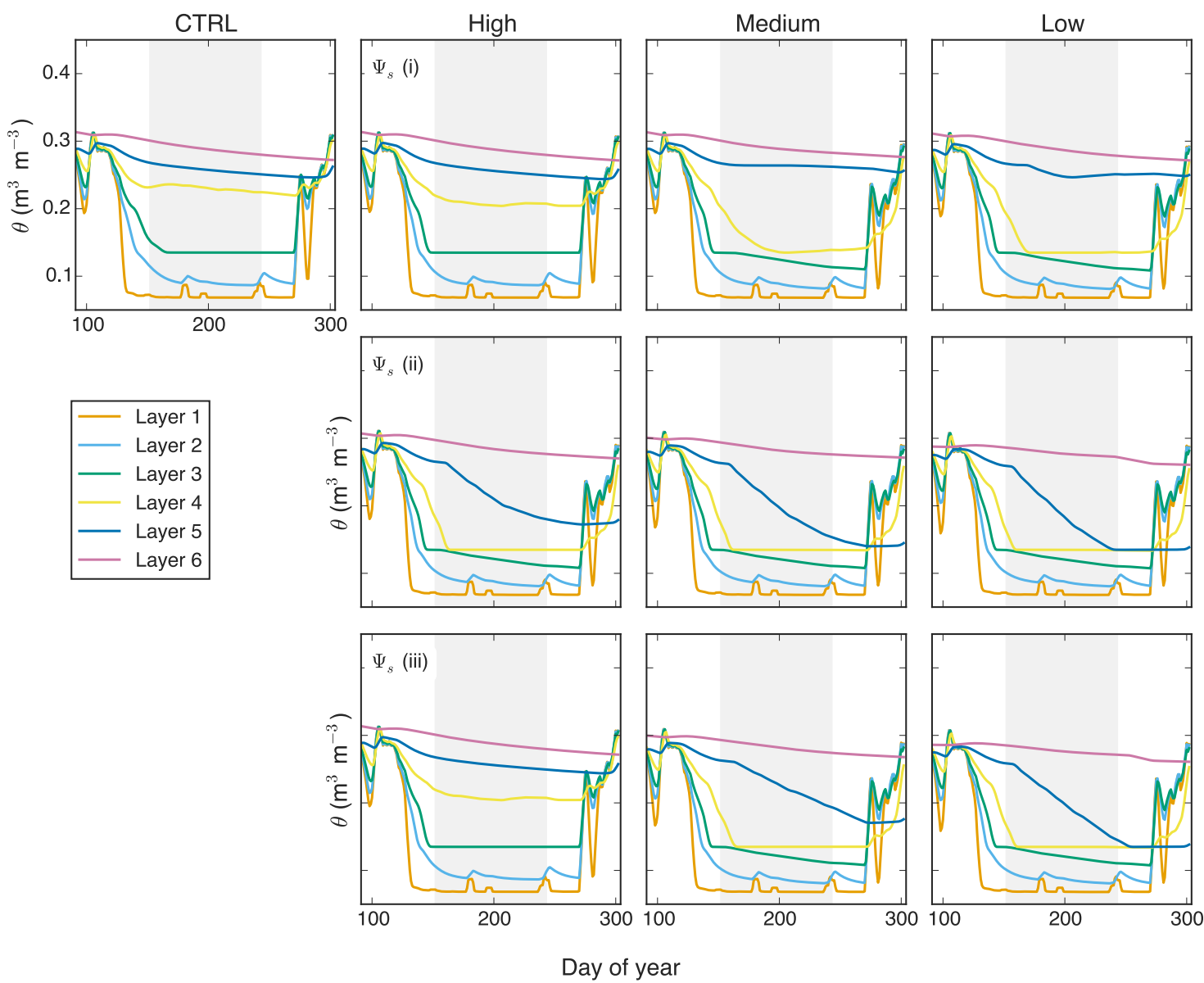